\title{
Aplikasi Pengisi Batang Sorgum pada Sintesis Bioplastik dengan Plasticizer PEG-400 dan Asam Palmitat
}

\author{
Yuli Darni ${ }^{1)}$, Dita Synthauli E ${ }^{2)}$, Erna Sartika Sinambela ${ }^{3)}$, Herti Utami ${ }^{4)}$ \\ 1,2,3,4 Jurusan Teknik Kimia, Fakultas Teknik, Universitas Lampung \\ Jl. Prof. Soemantri Brojonegoro No.1, Bandar Lampung, Indonesia \\ ${ }^{1)}$ yuli.darni@eng.unila.ac.id \\ 2) ditaevania.de@gmail.com \\ 3)erna_sartika@ymail.com \\ ${ }^{4)}$ herti.utami@eng.unila.ac.id
}

\begin{abstract}
Plastics are used for human use, creating side effects on the environment. The low level of degradation in the plastic makes the environment must accommodate so much plastic waste that causes pollution so that innovation is needed in the manufacture of plastics that can decompose in nature. This study discusses the use of sorghum stalk as a filler in the manufacture of bioplastic. Sorghum starch and chitosan as a bioplastic raw material with a palmitic acid and PEG-400 as a plasticizer. The purpose of this study was determined the effect of sorghum stalk as a filler (packing material) into mechanical properties of bioplastic. Bioplastic produced is expected to resemble a commercial LDPE plastic. Starch-chitosan formulations used in this study was $63: 35(w / w)$, the size of the starch and chitosan was 63 micron sieve, stirring time about 35 minutes and stirring velocity about $375 \mathrm{rpm}$ this research was also conducted various concentration of plasticizer $(10,15,23,27,33,35 \mathrm{wt} \%)$. Some analysis of the mechanical test (tensile strength, percent elongation, and modulus young), water resistance, density and FTIR has determined the characteristics of bioplastic. The best result in this research is bioplastic with 1 gr filler formulation at $10 \%$ plasticizer concentration with modulus young value characteristic about 126,145 MPa, the tensile strength of 7,028 $M P a$, extension percent about 5,517\%, density about 0,9 gr/mL, the water absorption of 38,88\%. The bioplastic characteristic already meet the LDPE plastic standard.
\end{abstract}

Keywords: Bioplastics, Filler, Sorghum, PEG-400, Palmitic Acid

\section{Pendahuluan}

Plastik merupakan salah satu bahan yang banyak digunakan dalam kehidupan sehari-hari. Kegunaan plastik meliputi banyak hal, antara lain kebutuhan rumah tangga, sebagai pelindung alat-alat listrik, dan banyak digunakan sebagai kemasan makanan. Plastik memiliki sifat yang ringan, mudah dibentuk dan kuat. Namun, disisi lain plastik merupakan salah satu penyumbang sampah terbesar untuk lingkungan. Plastik yang banyak digunakan sehari-hari memiliki tingkat degradasi yang rendah, sehingga dibutuhkan waktu lama untuk menguraikan plastik tersebut. Akibat dari rendahnya tingkat degradasi plastik adalah menumpuknya sampah plastik yang dapat mencemari lingkungan. Berdasarkan hal tersebut, maka dibutuhkan adanya alternatif pembuatan plastik yang dapat dengan mudah terurai di alam. Plastik ini diperoleh dari bahan yang mudah didapat dan tersedia di alam dalam jumlah besar dan murah tetapi mampu menghasilkan produk dengan kekuatan yang sama dan dapat terurai secara biologis atau yang dikenal dengan plastik biodegradable [1]. Bioplastik yang telah dibuat, diuji sifat fisik dan mekaniknya dan dibandingkan dengan sifat fisik dan mekanik plastik komersial LDPE (Low Density Polyethylene), sehingga diharapkan bioplastik yang dibuat dapat digunakan sebagai substitusi plastik komersial namun ramah lingkungan.

Berdasarkan penelitian sebelumnya, sifat fisik dan mekanik dari bioplastik sedikit demi sedikit diperbaiki dengan penambahan plasticizer gliserol untuk menambah sifat plastisnya dan biopolimer kitosan untuk meningkatkan kekuatan tarik dan memperbaiki ketahanan air dari bioplastik [2]. Jenis pati yang digunakan adalah pati sorgum. Kitosan dipilih sebagai biopolimer karena bersifat hidrofobik sehingga diharapkan bioplastik yang dihasilkan memiliki penyerapan air yang kecil. Plasticizer yang digunakan adalah gliserol karena gliserol merupakan golongan polyol yang bila bereaksi dengan kitosan dapat menghasilkan film plastik yang kuat dan fleksibel [3]. Hasil terbaik dari penelitian tersebut diperoleh pada formulasi pati dan kitosan 6,5:3,5 (gr/gr) dengan konsentrasi gliserol 10\%, kecepatan pengaduk $375 \mathrm{rpm}$. Berdasarkan analisis 
Chemica

Volume 4, Nomor 2, Desember 2017, 39-45

ISSN: $2355-8776$

yang dilakukan diperoleh persen penyerapan air 96,79\%, kuat tarik 20,9364 MPa, persen perpanjangan $29,35 \%$ dan modulus young 71,61 MPa.

Berdasarkan hasil penelitian yang dilakukan, maka bioplastik yang dihasilkan belum mampu menyerupai sifat fisik dan kimia plastik komersial. Karena itu dilakukan penelitian lebih lanjut dimana dalam penelitian ini divariasikan dua variabel, yaitu konsentrasi plasticizer $(10 \%, 15 \%, 23 \%, 27 \%$, 33\%, dan 35\%) dan penambahan Filler (0,25 gr, 0,5 gr, dan 1 gr). Dalam penelitian ini plasticizer yang digunakan adalah PEG400 serta asam palmitat. Variasi konsentrasi plasticizer dilakukan untuk memperoleh sifat mekanik yang menyerupai plastik komersial LDPE. Variasi penambahan filler dilakukan untuk meningkatkan kekuatan mekanis dan barrier properties pada pati. Variabel tetap yang digunakan pada penelitian ini mengacu pada hasil optimum penelitian yang telah dilakukan sebelumnya yaitu waktu pengadukan 35 menit [4], ukuran pati 63 mikron [5], formulasi pati-kitosan adalah 65:35 (gr/gr), suhu gelatinisasi $95{ }^{\circ} \mathrm{C}$ dan kecepatan pengadukan $375 \mathrm{rpm}[2]$.

\section{Metode Penelitian}

\section{Alat dan Bahan Baku}

Bahan

- Tepung sorgum yang berasal dari B2TP-BPPT Lampung Tengah

- Kitosan

- PEG-400

- Asam palmitat

- Aquades

- Asam asetat.

Alat

- Ayakan 63 Mikron

- Mortar

- Gelas Ukur (500, 200, 100, 50, dan 10)

- Water Bath

- Stirrer

\section{Prosedur Penelitian}

\section{Pembuatan Tepung Sorgum}

Sorgum dicuci untuk menghilangkan kotoran dan memisahkan biji sorgum yang berkualitas bagus dan tidak.

Tepung sorgum berukuran 63 mikron dikemas dengan ziplock untuk mencegah jamur dan kutu.

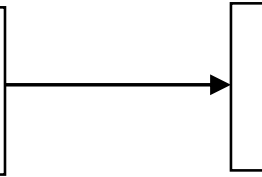

Sorgum dikeringan dengan menggunakan oven pada suhu $60{ }^{\circ} \mathrm{C}$ dengan lama pengeringan 3,5 jam.

\section{Pembuatan Pengisi Batang Sorgum}

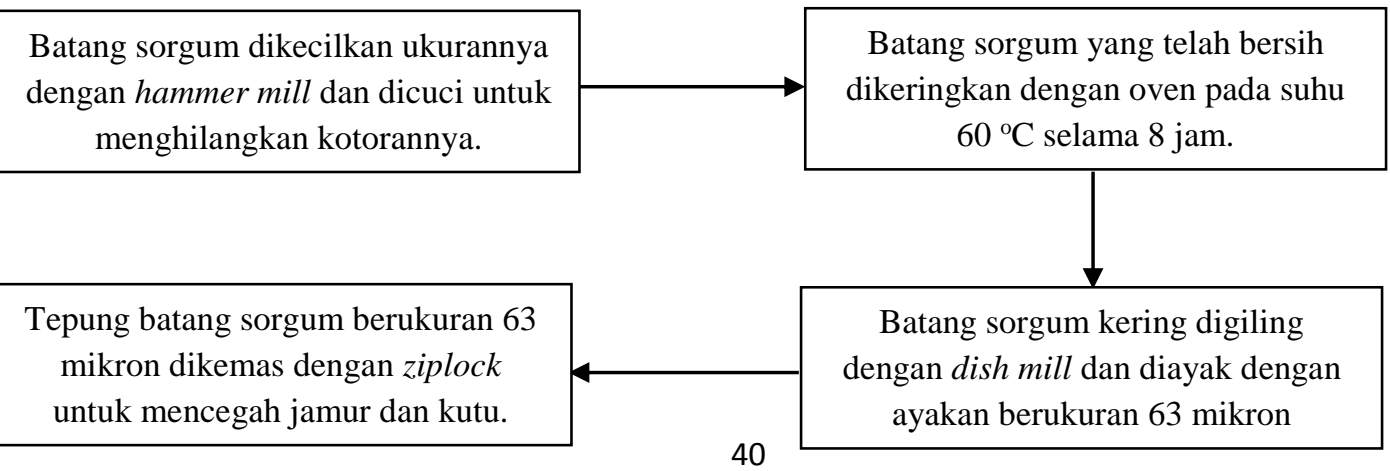




\section{Pembuatan Bioplastik}

- Pati ditimbang sebanyak 6,5 gram dan kitosan sebanyak 3,5 gram.

- PEG-400, asam palmitat, asam asetat, dan aquades diukur sesuai volume masing-masing.

- Pati dilarutkan dengan aquades dalam gelas beaker $500 \mathrm{ml}$, dan kitosan dilarutkan dengan asam asetat.

- PEG-400, asam palmitat, dan larutan kitosan dicampurkan ke dalam larutan pati dan diaduk dengan motor pengaduk dan jenis pengaduk turbin dengan temperatur pengadukan $95{ }^{\circ} \mathrm{C}$ selama 35 menit.

- Campuran bioplastik kemudian dicetak ke dalam piringan seng sebanyak $50 \mathrm{ml}$ pada masing-masing piring ditaruh dalam oven dengan temperatur $60^{\circ} \mathrm{C}$ selama 12 jam.

- Bioplastik dari oven didinginkan, kemudian bioplastik dilepaskan dari cetakan dan disimpan dalam zip bag lock. Plastik siap untuk dianalisis.

\section{Hasil Dan Pembahasan}

Pengaruh Konsentrasi Plasticizer (PEG-400 dan asam palmitat) dan Penambahan Filler terhadap Sifat Mekanik Bioplastik

\section{Kuat tarik}

Kuat tarik adalah salah satu uji untuk mengetahui tegangan maksimum suatu bahan. Kuat tarik pada bioplastik dipengaruhi oleh konsentrasi plasticizer. Pada Gambar 1 dapat dilihat pengaruh dari konsentrasi plasticizer dan penambahan filler terhadap kuat tarik yang dimiliki bioplastik.

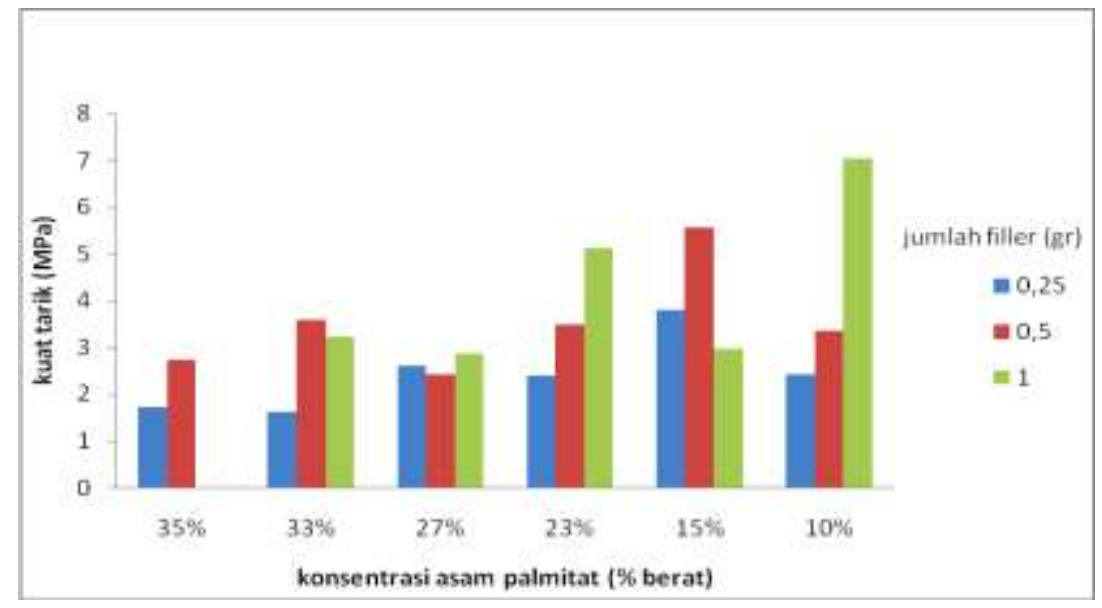

Gambar 1. Pengaruh konsentrasi plasticizer asam palmitat dan penambahan filler terhadap kekuatan tarik bioplastik

Besarnya kuat tarik dari bioplastik dipengaruhi oleh konsentrasi plasticizer-nya. Berdasarkan Gambar 1, nilai tertinggi dari kuat tarik pada bioplastik terdapat pada konsentrasi palsticizer $10 \%$ dan penambahan filler 1 gram dengan nilai 7,028168 MPa. Kuat tarik tersebut mengalami penurunan seiring dengan penambahan konsentrasi asam palmitat. Dari Gambar 1 dapat kita lihat bahwa semakin banyak asam palmitat maka semakin rendah kuat tariknya. Hal ini dikarenakan sifat asam palmitat yang mampu menurunkan gaya intermolekular sepanjang rantai polimer sehingga menyebabkan polimer lebih elastis dan menurunkan kuat tarik bahan tersebut [7].

Biopolimer lain yang mampu meningkatkan sifat mekanik bioplastik adalah selulosa dan gelatin. Salah satu kandungan dari filler yang digunakan pada penelitian ini adalah selulosa. Penambahan filler juga mempengaruhi kuat tarik dari bioplastik ini. Hal ini terlihat dari Gambar 1, semakin banyak filler yang ditambahkan ke dalam bioplastik maka semakin meningkat juga kuat tarik dari bioplastik tersebut.

Untuk membuat bioplastik yang dapat menggantikan plastik konvensional LDPE, maka kuat tarik yang dimiliki bioplastik tersebut harus memenuhi standar kuat tarik plastik konvensional LDPE yaitu 20,67-51,675 MPa. Dari Gambar 1 dapat dilihat bahwa kuat tarik terbesar diperoleh pada konsentrasi plasticizer $10 \%$ dan penambahan filler 1 gram sebesar 7,028168 MPa. Sehingga dapat disimpulkan bahwa kuat tarik bioplastik ini menyamai plastik konvensional LDPE. 
Chemica

Volume 4, Nomor 2, Desember 2017, 39-45

ISSN: $2355-8776$

\section{Persen Perpanjangan}

Persen perpanjangan merupakan besarnya keelastisan bioplastik saat ditarik hingga putus. Pengaruh dari konsentrasi plasticizer dan penambahan filler terhadap persen perpanjangan dapat dilihat pada Gambar 2.

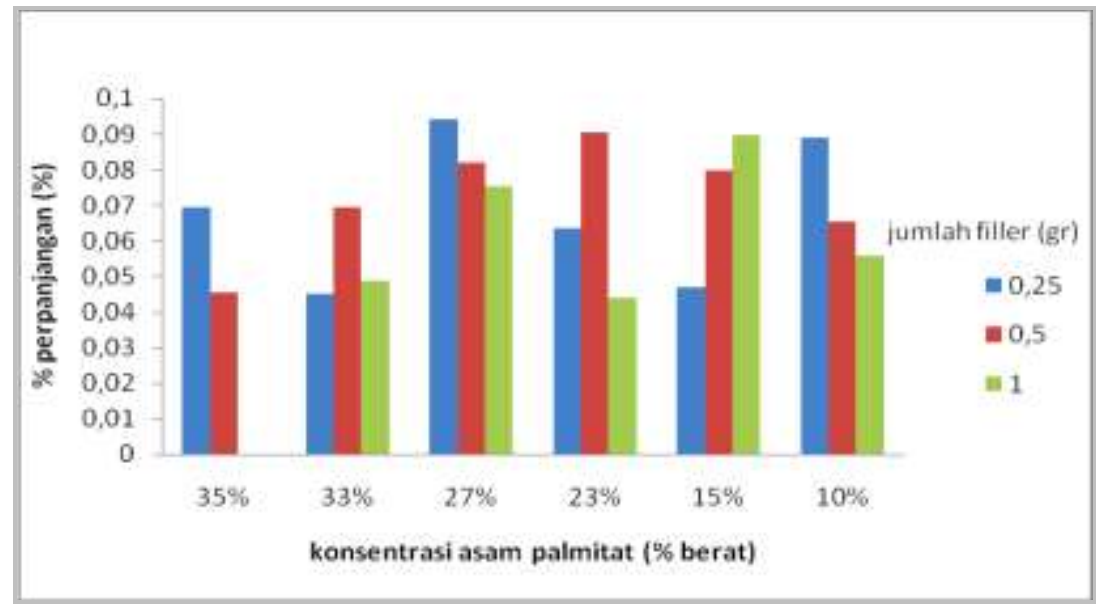

Gambar 2. Pengaruh konsentrasi plasticizer asam palmitat dan penambahan filler terhadap persen perpanjangan bioplastik

Persen Perpanjangan (Elongation at break) menunjukan keuletan suatu bahan bioplastik. Persen perpanjangan tertinggi terdapat pada konsentrasi plasticizer $27 \%$, yaitu sebesar $9,412 \%$. Range perpanjangan plastik konvensional LDPE adalah 225-600\%. Jika dilihat dari range perpanjangan plastik konvensional LDPE ini maka semua sampel bioplastik yang dihasilkan masih jauh dibawah rata-rata plastik konvensional.

Penambahan plasticizer juga mempengaruhi persen perpanjangan, dalam penelitian ini plasticizer yang digunakan adalah asam palmitat dengan pelarut PEG-400. Salah satu sifat dari PEG-400 yaitu sebagai proteksi yang baik untuk menghilangnya air dari bioplastik. Hal ini menjadi salah satu faktor yang membuat persen perpanjangan dari bioplastik sangat rendah.

\section{Modulus young}

Modulus young diperoleh dari perbandingan antara kekuatan tarik (tensile strength) terhadap persen perpanjangan (elongation at break). Modulus young sering dikatakan sebagai ukuran kekakuan suatu bahan. Pengaruh konsentrasi plasticizer dan penambahan filler terhadap Modulus young bioplastik dapat dilihat pada Gambar 3.

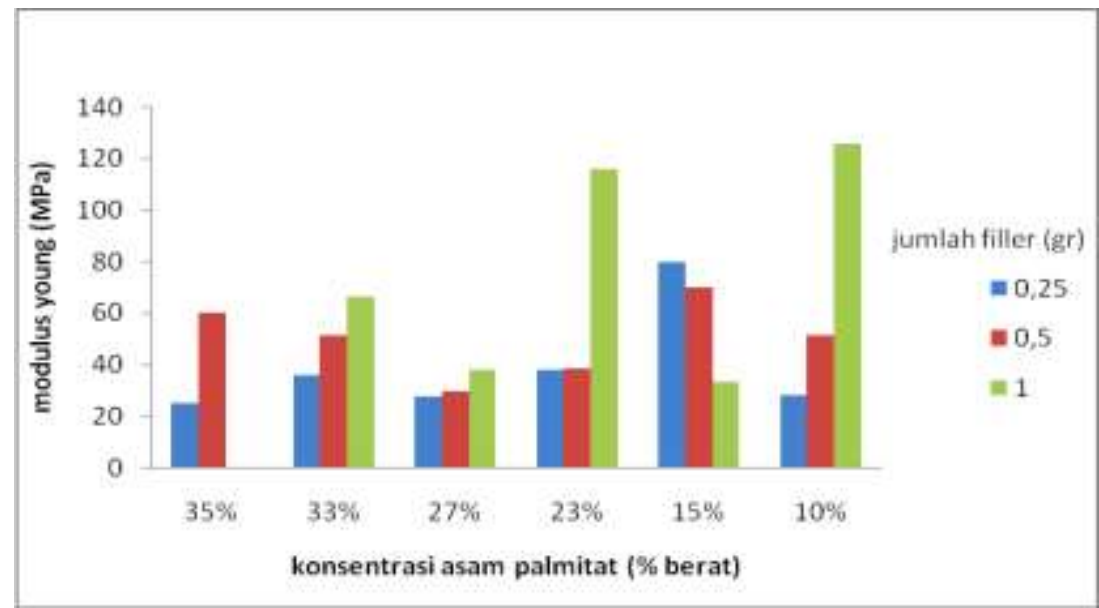

Gambar 3. Pengaruh konsentrasi plasticizer asam palmitat dan penambahan filler terhadap modulus young bioplastik

Dari Gambar 3. terlihat bahwa nilai modulus young nya cenderung mengalami penurunan pada saat penambahan konsentrasi plasticizer, tetapi adanya penambahan filler membuat modulus young nya cenderung naik. Pada konsentrasi plasticizer $10 \%$ dan formulasi filler 1 gram, modulus young mencapai nilai 
tertinggi yaitu 126,145 MPa. Nilai tersebut memenuhi standar modulus young LDPE yaitu 100-250 MPa. Untuk nilai modulus young terendah terdapat pada formulasi filler 0,25 gram, konsentrasi plasticizer 35\% dengan nilai 24,76795 MPa. Dari data bioplastik ini maka dapat ditarik kesimpulan bahwa penambahan filler pada bioplastik terbukti meningkatkan nilai modulus young bioplastik.

\section{Pengaruh Konsentrasi Plasticizer (PEG-400 dan Asam Palmitat) dan Penambahan Filler terhadap Sifat Fisik Bioplastik}

\section{Densitas}

Densitas atau kerapatan dapat didefinisikan sebagai massa per satuan volume bahan. Densitas atau kerapatan merupakan sifat fisik suatu polimer. Semakin rapat suatu bahan, maka sifat mekaniknya semakin baik sehingga film plastik yang dihasilkan mempunyai kekuatan tarik (tensile strength) yang baik. Densitas bioplastik ini ditentukan dengan menggunakan metode kenaikan fluida dalam gelas ukur. Pengaruh konsentrasi plasticizer dan penambahan filler terhadap densitas dapat dilihat pada Gambar 4.

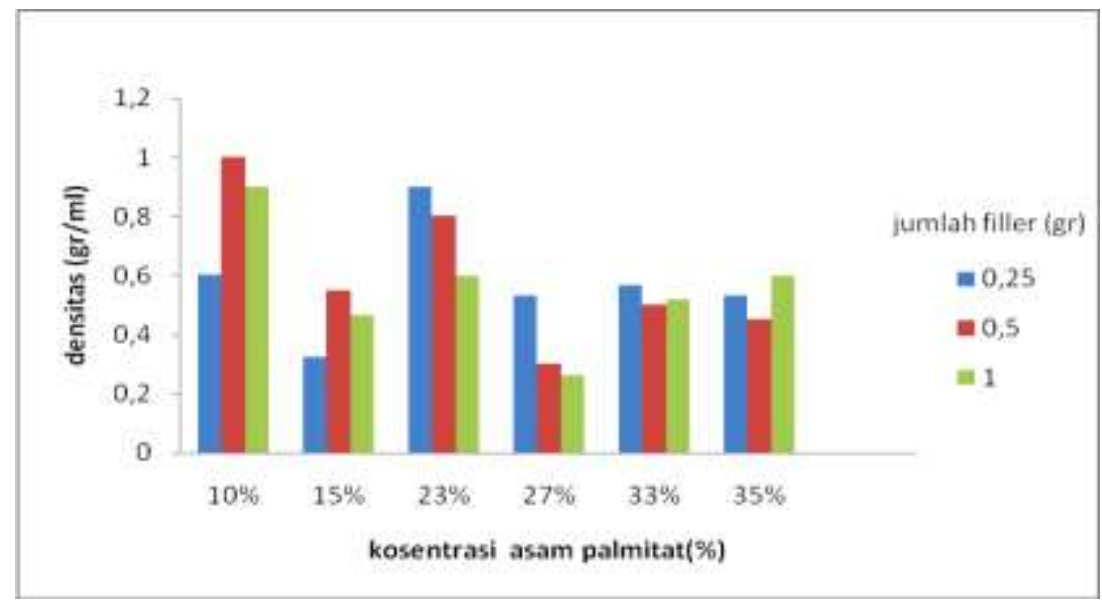

Gambar 4. Pengaruh konsentrasi plasticizer asam palmitat dan penambahan filler terhadap densitas bioplastik

Rentang densitas untuk plastik konvensional LDPE adalah 0,91-0,925 gr/ml [8]. Berdasarkan Gambar 4 terlihat bahwa pada konsentrasi plasticizer $10 \%$ dengan penambahan filler 0,5 gram sebagai run terbaik yang memiliki densitas $1 \mathrm{gr} / \mathrm{ml}$, lebih tinggi dari range minimum untuk plastik LDPE. Namun pada penelitian ini hasil yang menjadi titik acuannya yaitu pada konsentrasi plasticizer $10 \%$ dan penambahan filler 1 gram, dengan hasil densitasnya sebesar $0,9 \mathrm{gr} / \mathrm{ml}$. Nilai densitas pada konsentrasi ini mendekati nilai densitas untuk plastik LDPE.

\section{Analisis Gugus Fungsi}

Analisis gugus fungsi bioplastik dilakukan untuk mengindentifikasi struktur bioplastik baik yang mengandung senyawa organik maupun senyawa anorganik. Analisa gugus fungsi dilakukan dengan menggunakan Fourier Transform Infra Red Spectrofotometer (FTIR). Hasil analisa gugus fungsi pada bioplastik dapat dilihat pada Gambar 5 


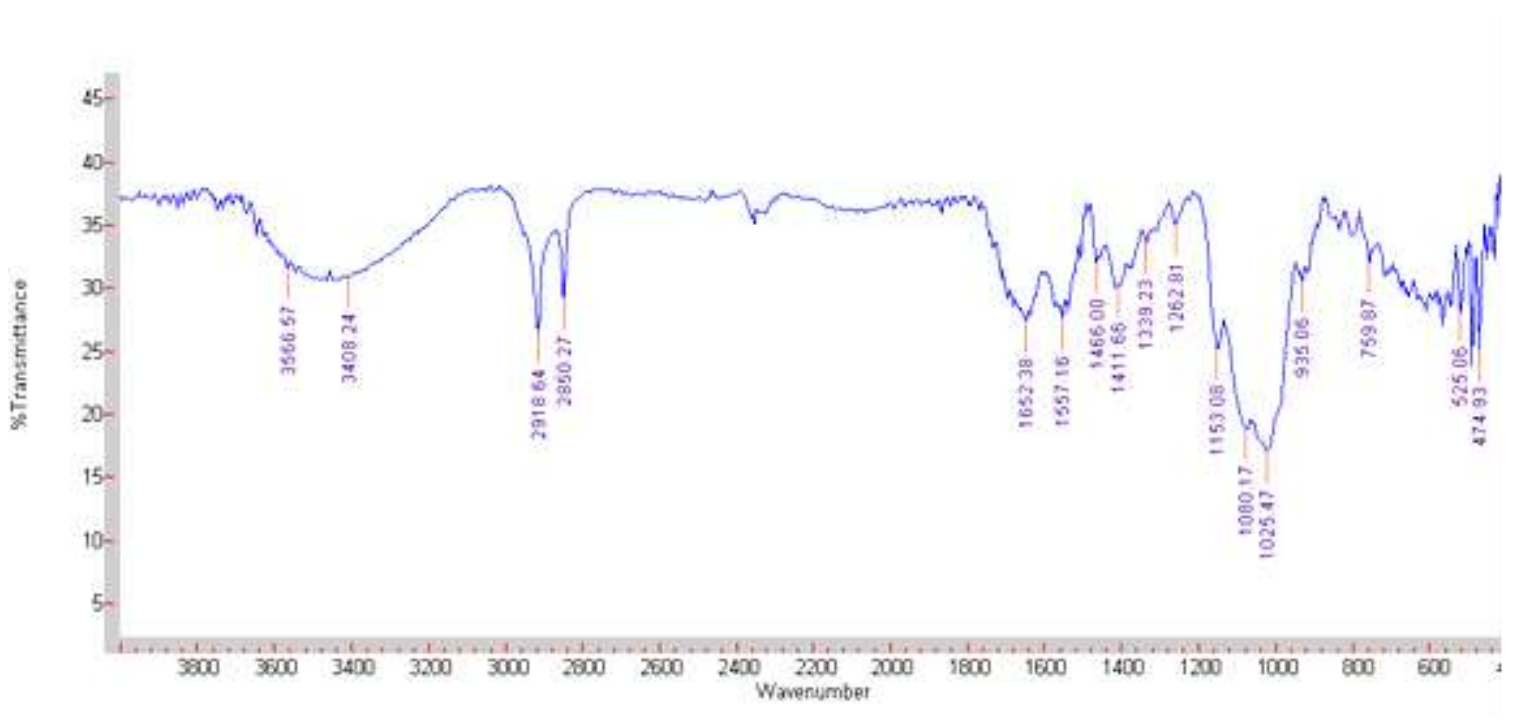

Gambar 5. Hasil FTIR pada bioplastik dengan konsentrasi plasticizer 35\% dan 1 gr filler

Tabel 1. Hasil analisis FTIR pada bioplastik

\begin{tabular}{|c|c|c|c|c|c|}
\hline \multicolumn{2}{|c|}{ 10\% PEG, 0,5 gr filler } & \multicolumn{2}{c|}{ 23\% PEG-400, 0,5 gr filler } & \multicolumn{2}{c|}{ 35\% PEG-400, 1 gr filler } \\
\hline $\begin{array}{c}\text { Bilangan } \\
\text { gelombang }\left(\mathbf{c m}^{-\mathbf{1}}\right)\end{array}$ & Identifikasi & $\begin{array}{c}\text { Bilangan } \\
\text { gelombang }\left(\mathbf{c m}^{-1}\right)\end{array}$ & identifikasi & $\begin{array}{c}\text { Bilangan } \\
\text { gelombang }\left(\mathbf{c m}^{-1}\right)\end{array}$ & Identifikasi \\
\hline $2850-3000$ & $\mathrm{C}-\mathrm{H}$ & $2850-3000$ & $\mathrm{C}-\mathrm{H}$ & $3580-3650$ & $\mathrm{O}-\mathrm{H}$ \\
\hline 1652,52 & $\mathrm{C}=\mathrm{C}$ & $1500-1560$ & $\mathrm{~N}-\mathrm{H}$ & 3408,24 & $\mathrm{~N}-\mathrm{H}$ \\
\hline $1500-1560$ & $\mathrm{~N}-\mathrm{H}$ & & & & \\
\hline $1350-1470$ & $\mathrm{CH}_{2}$ dan $\mathrm{CH}_{3}$ & $1350-1470$ & $\mathrm{CH}_{2}$ dan $\mathrm{CH}_{3}$ & $2850-3000$ & $\mathrm{C}-\mathrm{H}$ \\
\hline $1040-1100$ & $\mathrm{C}=\mathrm{O}$ & $1040-1100$ & $\mathrm{C}=\mathrm{O}$ & 1652,38 & $\mathrm{C}=\mathrm{C}$ \\
\hline $650-770$ & $\mathrm{O}-\mathrm{H}$ & 720 & $\mathrm{CH}_{2}$ & $1200-1020$ & $\mathrm{C}-\mathrm{OH}$ \\
\hline
\end{tabular}

Hasil analisis FTIR pada Gambar 5 dapat dilihat komposisi gugus fungsi yang terdapat pada bioplastik seperti ditunjukkan pada Tabel 1. Berdasarkan Tabel 1, kita dapat melihat bahwa kitosan memiliki dua gugus penting yaitu gugus hidroksil dan amina. Gugus hidroksil ( $-\mathrm{OH})$ terdapat pada puncak daerah 3580-3650. Puncak pada daerah 2850-3000 $\mathrm{cm}^{-1}$ menunjukkan serapan dari $\mathrm{C}-\mathrm{H}$. Untuk gugus amina $(\mathrm{N}-\mathrm{H}$ bend) menunjukkan serapan pada daerah $1500-1560 \mathrm{~cm}^{-1}$ dan terdapat ikatan $\mathrm{O}-\mathrm{H}$ bend yang ditunjukkan pada daerah 650-770 $\mathrm{cm}^{-1}$. Pada gambar tersebut juga terdapat gugus $\mathrm{CH}_{2}$ dan $\mathrm{CH}_{3}$ ditunjukkan pada daerah 1350$1470 \mathrm{~cm}^{-1}$, gugus $\mathrm{C}=\mathrm{O}$ pada daerah $1040-1100 \mathrm{~cm}^{-1}$.

Berdasarkan Gambar 5, gugus fungsi yang terdapat pada hasil analisis sampel bioplastik merupakan gabungan dari gugus fungsi spesifik yang terdapat pada komponen penyusunnya (pati, kitosan, asam asetat, PEG-400, dan asam palmitat). Dan dari sini juga terlihat bahwa tidak ditemukan gugus fungsi yang baru dan inilah yang menyebabkan bahan bioplastik tersebut masih memiliki sifat hidrofilik seperti sifat bahan penyusunnya sehingga mampu menyerap banyak air.

\section{Kesimpulan}

Berdasarkan hasil penelitian dapat disimpulkan bahwa penambahan filler meningkatkan sifat fisik dan mekanik bioplastik yang dihasilkan, namun penambahan plasticizer dapat menurukan \% perpanjangan. Hasil bioplastik terbaik yang diperoleh pada penelitian ini yaitu bioplastik dengan formulasi filler 1 gram pada konsentrasi plasticizer 10\%. Pada bioplastik tersebut diperoleh nilai modulus young sebesar 126,145 MPa, kuat tarik sebesar 7,028168 MPa, persen perpanjangan sebesar 5,5715\%, densitas $0,9 \mathrm{~g} / \mathrm{mL}$, daya serap terhadap air 38,88\%. Bioplastik yang dihasilkan pada dasarnya sudah memenuhi standar plastik LDPE yaitu dengan kuat tarik sebesar 7,028168 MPa, modulus young sebesar 126,145 $\mathrm{MPa}$, daya serap 38,88\% dan densitas $0,9 \mathrm{~g} / \mathrm{ml}$. Namun, bioplastik memiliki kekurangan yaitu persen perpanjangan yang tidak memenuhi standar plastik LDPE. 


\section{Ucapan Terima Kasih}

Peneliti mengucapkan terima kasih kepada Bapak Ir. Sabirin, M.Si. selaku Ketua Bidang Teknologi Diversifikasi B2TP-BPPT Desa Negara Bumi Hilir, Kecamatan Anak Tuha, Lampung Tengah yang telah membantu dalam penyediaan bahan baku pati sorgum dan batang sorgum guna memperlancar penelitian ini.

\section{Daftar Pustaka}

[1] -, 2017. Bioplastik, http://monruw.wordpress.com, 3 Desember 2011.

[2] Manalu, Santika. 2013. Pengaruh Konsentrasi Plasticizer terhadap Karakteristik Material Bioplastik yang Ramah Lingkungan. Seminar Nasional Material. ISBN: 978-602-19915-1-0.

[3] -, 2017. Gliserol, http://en.wikipedia.org/wiki/gliserol, 4 Desember 2011.

[4] Putri, L. S., 2012, Studi Optimasi Waktu dan Bilangan Reynold terhadap Sifat Fisik dan Mekanik dalam Pembuatan Bioplastik, Laporan Penelitian Teknik Kimia, Universitas Lampung, Bandar Lampung.

[5] Anggraini, A. S., 2011, Pengaruh Ukuran Partikel Sorgum Terhadap Sifat Fisik Dan Sifat mekanik Pada Sintesa Bioplastik, Laporan Penelitian Teknik Kimia, Universitas Lampung, Bandar Lampung.

[6] Yang, Li. 1997. Physicochemical Properties of Biodegradable/Edible Films Made With Gellan Gum, University of Nova Scotia, Canada.

[7] Rosato, D. 2004. Plastic Product Material \& Process Selection Handbook, Elsevier. 